\title{
Transvenous cardioversion for the management of recurrent ventricular arrhythmias
}

\author{
CLIFFORD A BUCKNALL, SUSAN LEWIS, RICHARD VINCENT, \\ GRAHAM JACKSON, DAVID E JEWITT, DOUGLAS A CHAMBERLAIN
}

From the Departments of Cardiology, Royal Sussex County Hospital, Brighton, and King's College Hospital, London

SUMMARY The efficacy of transvenous cardioversion and defibrillation for treating life threatening spontaneous ventricular arrhythmias was assessed in a study of 17 patients in a cardiac care unit. Eleven had ventricular tachycardia, five had ventricular fibrillation, and one had both. Transvenous cardioversion successfully terminated tachyarrhythmias on 42 separate occasions in ten patients. Stable electrode positions could not be achieved in two patients, recurrent late displacement occurred in one, and four patients had no further arrhythmias requiring cardioversion once the lead was placed. The energy levels required for successful cardioversion ranged from $0.05 \mathrm{~J}$ to $25 \mathrm{~J}$ for ventricular tachycardia and from $1 \mathrm{~J}$ to $25 \mathrm{~J}$ for ventricular fibrillation. The nine successful shocks of $1 \mathrm{~J}$ or less did not require sedation or general anaesthesia. High energy $(25 \mathrm{~J})$ endocardial shocks were unsuccessful in terminating arrhythmias in two patients, one with ventricular tachycardia and the other with both ventricular tachycardia and fibrillation. Minor unwanted effects of endocardial shocks occurred in five patients. These were acceleration of ventricular tachycardia in two patients and complications of pacing via the special lead in three others: failure of sensing occurred in all three and one patient also had a transient rise in pacing threshold. A postmortem examination in one patient who had received three unsuccessful high energy shocks revealed localised endocardial necrosis at the site of the distal electrode.

Transvenous cardioversion offers advantages over external cardioversion but at present practical difficulties limit its application to patients with recurrent ventricular arrhythmias that cannot readily be controlled by conventional methods.

Electrical treatment of life threatening ventricular arrhythmias occurring after myocardial infarction poses several problems; these include the need for repeated general anaesthetics, delays before cardioversion, and superficial burns. Nevertheless, the long term prognosis can be good in those patients who survive the unstable acute phase. Although low energy endocardial shocks have been shown to terminate ventricular arrhythmias induced during electrophysiological testing, ${ }^{1-3}$ little experience of the use of transvenous cardioversion with an external unit has been reported for spontaneous ventricular arrhythmias. ${ }^{24}$ We have tested the applicability of this technique to patients in a cardiac care unit.

Requests for reprints to Dr Douglas A Chamberlain, Royal Sussex County Hospital, Eastern Road, Brighton, Sussex BN2 5BE.

Accepted for publication 12 May 1987

\section{Patients and methods}

We studied 11 men and six women (aged 46-75 years) with recurrent ventricular arrhythmias; eleven had recurrent ventricular tachycardia, five had recurrent ventricular fibrillation, and one had both. All but one patient had sustained a recent acute myocardial infarction. One patient was treated for malignant postoperative ventricular arrhythmias. A median of four attacks (2-30) of a ventricular arrhythmia occurred before transvenous cardioversion was attempted. All patients had been treated with antiarrhythmic drugs in the cardiac care unit of the Royal Sussex County Hospital, Brighton or King's College Hospital, London. Table 1 summarises the patient data.

The temporary pacing lead (Medtronic 6880, Medtronic Inc, Minneapolis, USA) designed for 
Table 1 Patient details

\begin{tabular}{|c|c|c|c|c|c|c|}
\hline Patient No & Age & Sex & Clinical diagnosis & $\begin{array}{l}\text { Recurrent } \\
\text { arrhythmia }\end{array}$ & $\begin{array}{l}\text { No of } \\
\text { episodes }\end{array}$ & $\begin{array}{l}\text { Previous } \\
\text { drug } \\
\text { treatment }\end{array}$ \\
\hline $\begin{array}{l}1 \\
2 \\
3 \\
4 \\
5 \\
6 \\
7 \\
8 \\
9 \\
10 \\
11 \\
12 \\
13 \\
14 \\
15 \\
16 \\
17 \\
\text { Mean } \\
\end{array}$ & $\begin{array}{l}53 \\
69 \\
72 \\
59 \\
74 \\
76 \\
72 \\
67 \\
46 \\
61 \\
63 \\
69 \\
60 \\
61 \\
57 \\
59 \\
75 \\
64\end{array}$ & $\begin{array}{l}F \\
\text { F } \\
M \\
M \\
M \\
M \\
M \\
F \\
F \\
M \\
F \\
M \\
M \\
M \\
M \\
F \\
11 M / 6 F\end{array}$ & $\begin{array}{l}\text { MI } \\
\text { Hysterectomy } \\
\text { MI } \\
\text { MI } \\
\text { MI } \\
\text { MI } \\
\text { MI } \\
\text { MI } \\
\text { MI } \\
\text { MI } \\
\text { MI } \\
\text { MI } \\
\text { MI } \\
\text { MI } \\
\text { MI } \\
\text { MI } \\
\text { MI }\end{array}$ & $\begin{array}{l}\text { VF } \\
\text { VF } \\
\text { VF } \\
\text { VF } \\
\text { VF/VT } \\
\text { VT } \\
\text { VT } \\
\text { VT } \\
\text { VT } \\
\text { VT } \\
\text { VT } \\
\text { VT } \\
\text { VT } \\
\text { VT } \\
\text { VT } \\
\text { VT }\end{array}$ & $\begin{array}{c}5 \\
3 \\
6 \\
4 \\
3 \\
4 \\
3 \\
3 \\
4 \\
3 \\
5 \\
30^{\star} \\
11 \\
3 \\
3 \\
4 \\
2\end{array}$ & $\begin{array}{l}\text { L, Am } \\
\text { L } \\
\text { L } \\
\text { L, Am, Fl } \\
\text { L, Am } \\
\text { L, Am, Fl, } P \\
\text { L, Fl } \\
\text { L, Am, M } \\
\text { A, M } \\
\text { L, P } \\
\text { M, Am, Fl } \\
\text { L, Am, Fl, M } \\
\text { L, Am, Fl, P } \\
\text { L, Am } \\
\text { L } \\
\text { L, Am, } P \\
\text { L } \\
\text { 2.3 drugs } \\
\quad \text { per patient }\end{array}$ \\
\hline Median & & & & & 4 & \\
\hline
\end{tabular}

$\star 28$ of the 30 shocks were given in Lewisham Hospital.

Am, amiodarone; Fl, flecainide; L, lignocaine; M, mexiletine; MI, myocardial infarction; P, procainamide; VF, ventricular fibrillation; VT, ventricular tachycardia.

transvenous cardioversion has bipolar pairs of stainless steel electrodes-at the tip in the right ventricular apex and $13 \mathrm{~cm}$ proximally to lie near the junction of the right atrium and superior vena cava. The electrodes in each pair are separated by $5 \mathrm{~mm}$ and have a combined surface area of $125 \mathrm{~mm}^{2}$. When the shock is delivered the two distal electrodes are coupled together to form the cathode and the two proximal electrodes to form the anode. The distal pair is used for sensing to synchronise cardioversion, and can also provide bipolar pacing. The lead was introduced through a 10.5 French gauge split sheath introducer into a subclavian vein in 13 patients and in the remaining four patients via an antecubital vein or an external jugular vein. We used a central stylet to manipulate the lead in a manner similar to that used for permanent pacing.

The cardioverter defibrillator used in this study was a purpose built manually operated device (Medtronic 5350, Medtronic Inc., Minneapolis, USA) that delivers a truncated exponential waveform. The waveform is described in terms of the relation of the voltage of the trailing edge to the leading edge. This is called "tilt" (fig 1). The percentage tilt is the percentage decrease between the leading edge and the trailing edge voltage. Three different tilts were available, namely, $27 \%, 63 \%$, or $82 \%$. The shocks used throughout the study had $63 \%$ tilt

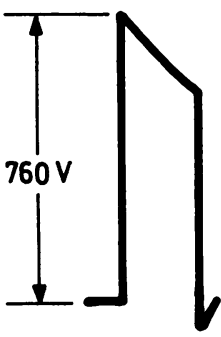

Energy

$8.1 \mathrm{~J}$

Tilt $27 \%$

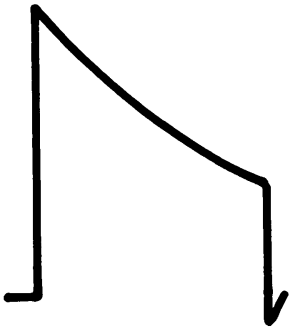

$15.0 \mathrm{~J}$ $63 \%$ $6 \mathrm{~ms}$

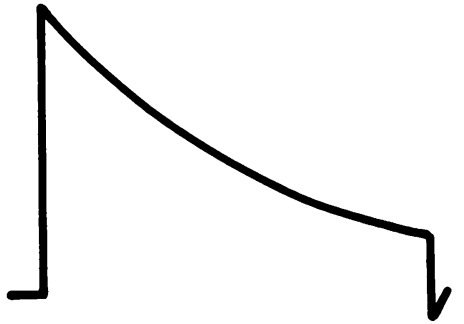

$16.8 \mathrm{~J}$ $82 \%$ $10 \mathrm{~ms}$

\section{* For discharge over a $100 \Omega$ load}

Fig 1 The leading edge voltage for all three waveforms shown above is $760 \mathrm{~V}$. The percentage tilt refers to the percentage decrease between the leading edge and the trailing edge voltage. 
Table 2 Energy levels used for transvenous cardioversion

\begin{tabular}{|c|c|c|c|c|c|c|c|c|c|c|c|c|}
\hline & \multicolumn{12}{|c|}{ Attempt } \\
\hline & 1 & 2 & 3 & 4 & 5 & 6 & 7 & 8 & 9 & 10 & 11 & 12 \\
\hline \multirow{2}{*}{$\begin{array}{l}\text { Energy (J) } \\
\text { Leading edge } \\
\text { voltage (V) }\end{array}$} & 0.05 & $0 \cdot 10$ & 0.25 & 0.50 & 1.00 & 1.50 & $2 \cdot 0$ & $5 \cdot 0$ & $10 \cdot 0$ & $15 \cdot 0$ & $20 \cdot 0$ & $25 \cdot 0$ \\
\hline & 44 & 60 & 98 & 132 & 193 & 236 & 271 & 436 & 610 & 747 & 686 & 971 \\
\hline
\end{tabular}

Tilt of $63 \%$ and pulse width of $6 \mathrm{~ms}$ used throughout.

and lasted six seconds. An energy level of $0.05 \mathrm{~J}$ was used for the first attempt at cardioversion and this was increased by 11 steps until success was achieved or a maximum output of $25 \mathrm{~J}$ had been used (table 2 ). If an arrhythmia recurred, the energy level chosen for the next attempt at cardioversion was set at one step lower than that used in the previous successful cardioversion. In patients with ventricular tachycardia discharge delivery was synchronised by means of the apical right ventricular electrogram. The charging time for the cardioverter defibrillator was less than 10 seconds even for high energy shocks. Sedation or general anaesthesia was used if shocks caused appreciable discomfort.

When necessary, ventricular pacing could be provided by connecting an external pulse generator to the cardioverter defibrillator. Simultaneous defibrillation and pacing was prevented by a switch that allowed choice between pacing, synchronised shock, or asynchronous shock.

\section{Results}

In 14 of the 17 patients the pacing lead was positioned successfully and remained stable. Of these 14, 10 had further tachycardia that required cardioversion; all were successfully treated at least once. Three had ventricular fibrillation, six had ventricular tachycardia, and one patient had both. Tachycardia was terminated on 42 separate occasions. Figure 2 shows an example of successful transvenous cardioversion.

Four patients in whom the lead remained stable did not receive endocardial shocks. Three settled on antiarrhythmic treatment once the lead was in position, while one patient developed self-terminating multiform ventricular tachycardia that was suppressed successfully by ventricular overdrive pacing via the special lead. In the three remaining patients difficulties were experienced with lead placement or subsequent lead stability: in one, ventricular fibrillation was triggered repeatedly on crossing the tricuspid valve; in the second, instability prevented initial lead placement; in the third, the procedure was abandoned because of repeated lead displacement.
The energy levels associated with successful cardioversion varied from $0.05 \mathrm{~J}$ to $25 \mathrm{~J}$ (median $10 \mathrm{~J}$ ). Ventricular tachycardia was terminated by synchronised shocks of $0.05 \mathrm{~J}-25 \mathrm{~J}$ (median $2 \mathrm{~J}$ ) and ventricular fibrillation by asynchronous shocks ranging from $1 \mathrm{~J}$ to $25 \mathrm{~J}$ (median $10 \mathrm{~J}$ ). The difference between the mean energy levels required for cardioversion of tachycardia and fibrillation did not reach statistical significance. Perception of discomfort caused by transvenous cardioversion varied, but the nine successful shocks of $1 \mathrm{~J}$ or less did not cause undue discomfort and required neither sedation nor general anaesthesia.

Transvenous cardioversion failed to terminate some episodes of ventricular arrhythmias in two patients. High energy (25 J) endocardial shocks were unsuccessful in terminating ventricular tachycardia in one patient and ventricular tachycardia or fibrillation in another; sinus rhythm was restored in each case by external countershock. In both of these patients further arrhythmias did respond to transvenous cardioversion. Subsequently these two patients died of intractable cardiac failure. Necropsy in one who had received three unsuccessful high energy shocks revealed an area of myocardial necrosis to a depth of $0.5 \mathrm{~cm}$ around the distal tip of the lead.

Unwanted effects of transvenous cardioversion occurred in five patients. Two of them had acceleration of ventricular tachycardia or provocation of ventricular fibrillation in response to synchronised low energy shocks (fig 3). Reversion to sinus rhythm was achieved by higher energy endocardial shock and by external countershock. The unwanted effects of transvenous cardioversion in the three other patients were related to pacing after endocardial shock. Although pacing was achieved satisfactorily in most patients who required it, inappropriate pacing due to failure of sensing after endocardial shock occurred in each of these three patients. In addition, one had a transient rise in pacing threshold from $0.7 \mathrm{~V}$ to $2 \cdot 4 \mathrm{~V}$.

Table 3 summarises the clinical outcome of all the patients. After the acute phase had settled, the tachycardia in nine of the 17 patients was suppressed by antiarrhythmic drugs, two underwent left ven- 

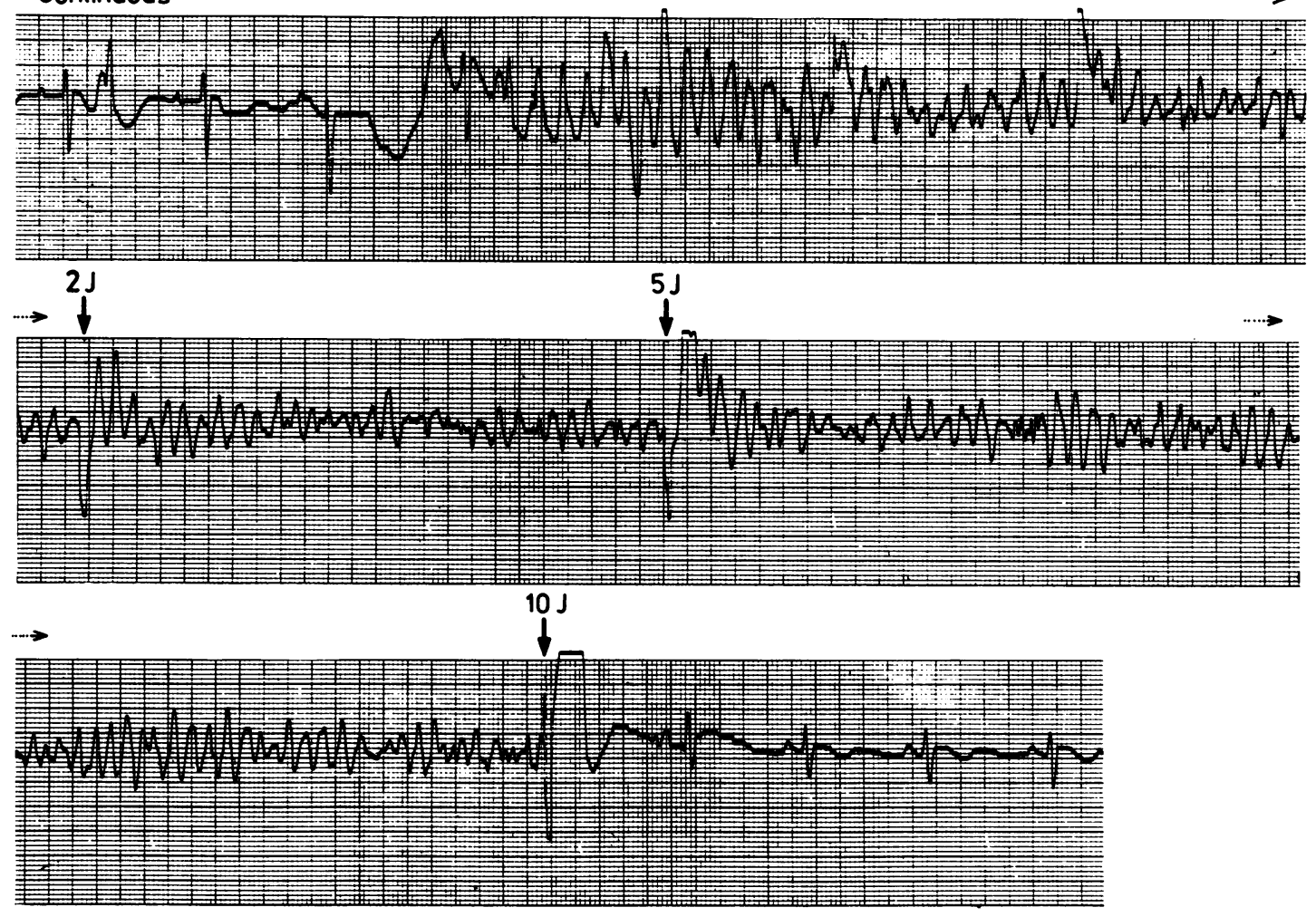

Fig 2 Successful transvenous cardioversion $(10 \mathrm{~J})$ in a patient with recurrent ventricular fibrillation. $A 5 \mathrm{~J}$ endocardial shock had been successful before. On this occasion transvenous cardioversion with shocks of $2 \mathrm{~J}$ and $5 \mathrm{~J}$ was unsuccessful but sinus rhythm was restored after a $10 \mathrm{~J}$ shock.

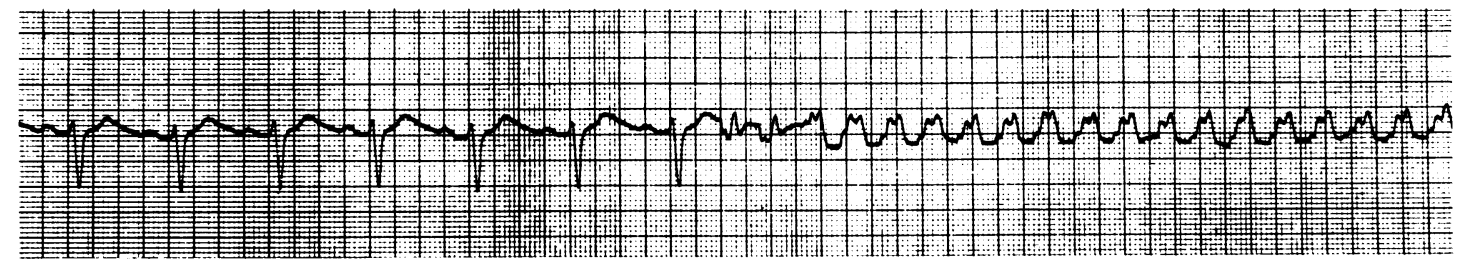

$2 \mathrm{~J}$

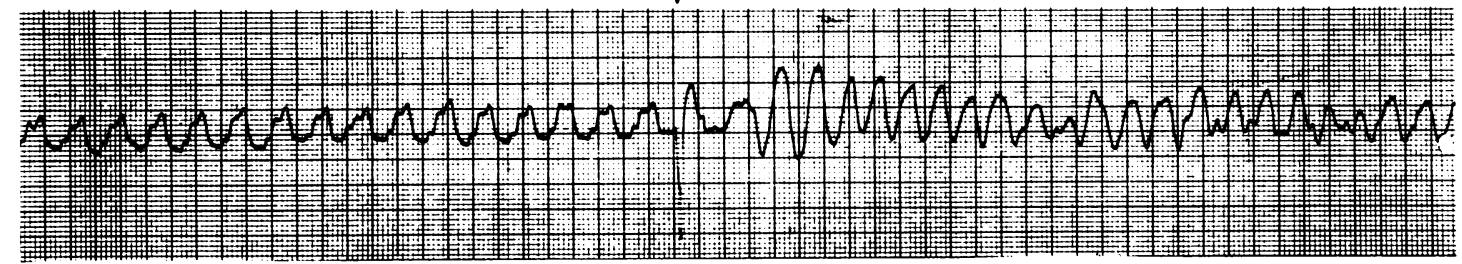

Fig 3 Provocation of ventricular fibrillation by a synchronised low energy shock. The top panel shows the onset of ventricular tachycardia. In the lower panel treatment of this ventricular tachycardia by a synchronised endocardial shock $(2 \mathrm{~J})$ provoked the onset of ventricular fibrillation. 
Table 3 Results and clinical outcome

\begin{tabular}{|c|c|c|c|c|c|}
\hline $\begin{array}{l}\text { Patient } \\
\text { No }\end{array}$ & Arrhythmia & $\begin{array}{l}\text { Successful } \\
\text { cardioversions }\end{array}$ & $\begin{array}{l}\text { Unsuccessful } \\
\text { cardioversions }\end{array}$ & $\begin{array}{l}\text { Mean energy } \\
\text { level }\end{array}$ & $\begin{array}{l}\text { Clinical } \\
\text { outcome }\end{array}$ \\
\hline 1 & VF & 3 & - & 6.0 & \multirow{6}{*}{$\begin{array}{l}\text { M (Am, D) } \\
\text { Died } \\
\text { Died } \\
\text { Surgery } \\
\text { Died }\end{array}$} \\
\hline 2 & VF & 5 & - & 11.0 & \\
\hline 3 & VF & 2 & - & 15.0 & \\
\hline 4 & VF & NFA & - & - & \\
\hline 5 & VF & LP & $\bar{F}$ & $\overline{100}$ & \\
\hline 6 & VT/ & 5 & $\mathbf{F}$ & $18 \cdot 0\}$ & \\
\hline 7 & $\begin{array}{l}\text { VF } \\
\text { VT }\end{array}$ & $\begin{array}{l}2 \\
7\end{array}$ & $\underline{F}$ & $\begin{array}{r}23.0 \\
7.8\end{array}$ & \multirow{11}{*}{$\begin{array}{l}\mathbf{M}(\mathrm{Fl}) \\
\mathbf{M}(\mathrm{Am}) \\
\text { Surgery } \\
\mathbf{M}(\mathrm{Am}) \\
\mathbf{M}(\mathrm{Am}) \\
\mathbf{M} \text { (Pr) } \\
\text { Died } \\
\mathbf{M}(\mathrm{Am}) \\
\mathbf{M}(\mathrm{Am}) \\
\mathbf{M}(\mathrm{Am}) \\
\mathbf{M} \text { (Am, Pr) } \\
\text { Pacemaker }\end{array}$} \\
\hline 8 & $\mathbf{V T}$ & 3 & - & 1.5 & \\
\hline 9 & VT & 1 & - & 0.5 & \\
\hline 10 & VT & 2 & A & 6.0 & \\
\hline 11 & $\mathrm{VT}$ & 6 & A & 0.4 & \\
\hline 12 & VT & 6 & $\mathbf{F}$ & 25.0 & \\
\hline 13 & VT & NFA & - & - & \\
\hline 14 & VT & NFA & - & - & \\
\hline 15 & VT & LP & - & - & \\
\hline 16 & VT & LP & - & - & \\
\hline 17 & VT & M1 & - & - & \\
\hline
\end{tabular}

$A$, acceleration of ventricular tachycardia or provocation of ventricular fibrillation; Am, amiodarone; $D$, disopyramide; $F$, failed cardioversion (25 J); Fl, flecainide; LP, lead placement problem; M, stabilised on medical treatment; Ml, multiform ventricular tachycardia suppressed by overdrive pacing; NFA, no further arrhythmias; Pr, procainamide; VF, ventricular fibrillation; VT, ventricular tachycardia.

tricular aneurysmectomy, and one received a permanent pacemaker. The remaining five patients died from intractable cardiac failure.

\section{Discussion}

Low energy endocardial shocks $(8 \mathrm{~mJ}$ to $1 \mathrm{~J}$ ) were reported in 1982 to be effective in terminating ventricular tachycardia in dogs. ${ }^{5}$ Subsequent studies of patients with inducible ventricular tachycardia found that reversion to sinus rhythm using intracavity shocks could be achieved in $60-80 \%$ of cases by energy levels of $\leqslant 30 \mathrm{~J}^{136}$ The technique, however, has not yet been fully evaluated. Possible benefits of transvenous cardioversion over conventional external countershock in the treatment of spontaneous recurrent ventricular arrhythmias include a reduction in the delays to cardioversion, less need for general anaesthetics, and no superficial burns. The interval between the onset of arrhythmia and cardioversion was not timed accurately in this study but transvenous cardioversion was associated with little delay provided that the patient was unconscious or responded to a low energy $(<1 \mathrm{~J})$ shock that required no sedation. In conscious patients higher energy endocardial shocks required the intravenous administration of a benzodiazepine and the delay before cardioversion was similar to that for external countershock. No patient required a general anaesthetic.

The present study is one of the largest so far reported of the use of transvenous cardioversion for spontaneous ventricular arrhythmias. In 1982 Yee et al reported early experience of using endocardial shocks to treat ventricular tachyarrhythmias in patients in a cardiac care setting. ${ }^{4}$ In their report of eight patients, transvenous cardioversion was used successfully to terminate $95 \%$ of 91 episodes of ventricular tachycardia, three episodes of ventricular flutter, and four of six episodes of ventricular fibrillation. Other reports of the use of transvenous cardioversion have concentrated upon the treatment of ventricular arrhythmias induced during electrophysiological testing rather than arising spontaneously. ${ }^{127}$

The energy levels required for successful cardioversion of spontaneous ventricular arrhythmias by endocardial shock varied widely. This variation in a small series would mask any tendency to a difference in the energy levels required for ventricular tachycardia and ventricular fibrillation. In a study of ventricular arrhythmias induced during electrophysiological testing, Waspe et al reported that higher energy levels were needed for conversion of ventricular fibrillation (mean $20.4 \mathrm{~J}$ ) than for most episodes of ventricular tachycardia (mean $1.4 \mathrm{~J}$ ). ${ }^{3}$ Moreover, Perelman et al suggested an inverse relation between the threshold for termination and the cycle length of ventricular tachycardia. ${ }^{8}$ The evidence from this study does not militate against these findings.

Although transvenous cardioversion was successful for the majority of patients in this study, several important problems were revealed. Difficulties with lead placement and stability precluded the use of this treatment in three of our patients. Modification of the special pacing lead with reduction of the 
stiffness of the tip of the lead may ease lead placement and improve stability. In addition to problems related to the lead, several unwanted effects occurred as a result of endocardial shocks: acceleration of ventricular tachycardia or provocation of ventricular fibrillation after a synchronised shock has already been reported after transvenous cardioversion ${ }^{2}$ and was related to the timing of the discharge within the QRS complex. ${ }^{58}$ Moreover, the usefulness of pacing via the special lead may be limited by the failure of sensing and increased pacing threshold after shocks; Yee et al reported similar findings in $1984 .{ }^{9}$ Internal cardioversion is not painless: patients receiving energy levels greater than $1 \mathrm{~J}$ required sedation and other groups have reported a similar pain threshold. ${ }^{127}$ Further research is also needed to establish whether localised myocardial necrosis found at the site of delivery of high energy endocardial shocks has greater clinical importance than the more diffuse myocardial damage after repeated external countershock. ${ }^{10}$

Transvenous cardioversion offers advantages over external countershock but at present practical difficulties limit its application to patients with recurrent ventricular arrhythmias that cannot readily be controlled by conventional methods.

Medtronic Incorporated, Minneapolis, provided the cardioverter defibrillator and special leads.

\section{References}

1 Ciccone JH, Saksena S, Shah Y, Pantopoulos D. A prospective randomised study of the clinical efficacy and safety of transvenous cardioversion for termination of ventricular tachycardia. Circulation 1985;71:571-8.

2 Nathan AW, Bexton RS, Spurrell RAJ, Camm AJ.
Internal transvenous low energy cardioversion for the treatment of cardiac arrhythmias. Br Heart $J$ 1984;52:377-84.

3 Waspe LE, Kim SG, Matos JA, Fisher JD. Role of a catheter lead system for transvenous countershock and pacing during electrophysiological tests: an assessment of the usefulness of catheter shocks for terminating ventricular tachyarrhythmias. $A m \mathrm{~J}$ Cardiol 1983;52:477-84.

4 Yee R, Zipes DP, Gulamhusein S, Kallok MJ, Klein GJ. Low energy countershock using an intravascular catheter in an acute cardiac care setting. $\mathrm{Am} \mathrm{J} \mathrm{Cardiol}$ 1982;50:1124-9.

5 Jackman WM, Zipes DP. Low energy synchronous cardioversion of ventricular tachycardia using a catheter electrode in a canine model of subacute myocardial infarction. Circulation 1982;66:187-95.

6 Saksena S, Chandran P, Shah Y, Boccadamo R, Pantopoulos D, Rothbart ST. Comparative efficacy of transvenous cardioversion and pacing in patients with sustained ventricular tachycardia: a prospective, randomised, crossover study. Circulation 1985;72: 153-60.

7 Zipes DP, Jackman WM, Heger JJ, et al. Clinical transvenous cardioversion of recurrent life-threatening arrhythmias: low energy synchronised cardioversion of ventricular tachycardia and termination of ventricular fibrillation in patients using a catheter electrode. Am Heart J 1982;103:789-94.

8 Perelman MS, Rowland E, Krikler DM. Assessment of a prototype implantable cardioverter for ventricular tachycardia. Relation between synchronisation of sensing and origin of the tachycardia. Br Heart $J$ 1984;52:385-91.

9 Yee R, Jones Klein GJ. Pacing threshold changes after transvenous cardioversion. Am J Cardiol 1984;53: 503-7.

10 Dahl C, Ewy GA, Warner ED, Thomas ED. Myocardial necrosis from direct current counter-shock: effect of paddle electrode size and time interval between discharges. Circulation 1974;50:956-61. 